\title{
Herpesvirus Infection in Development of Hemorrhagic Vascu- litis in Children (Literature Review)
}

\author{
M.A. Mamyrbayeva ${ }^{1 *}$, Zh.H. Isanguzhina ${ }^{2}$, A.B. Shilmanova ${ }^{1}$, N.M. Nurgaliev ${ }^{1}$, G.K. Ismambetova ${ }^{1}$ \\ ${ }^{1}$ Department of General Medical Practice No 1, West Kazakhstan Marat Ospanov State Medical University, \\ 68 Maresiyev Str., Aktobe, 030019, Kazakhstan \\ ${ }^{2}$ Department of Children's Diseases No 2, West Kazakhstan Marat Ospanov State Medical University, \\ 68 Maresiyev Str., Aktobe, 030019, Kazakhstan \\ *Corresponding author E-mail: mamyrbayeva.m.a@mail.ru
}

\begin{abstract}
The authors conducted a systematic review of the literature published in the last fifteen years. The results of the literature review showed that the role of herpesvirus infection in the occurrence of primary vasculitis is not excluded. In the works of Kazakhstan and foreign researchers who consider that ability of viruses to cytopathic effect is important for herpesvirus infection, herpes simplex infection is not excluded as a leading factor in the development of HV. In this regard, the study of the etiology of HV will help to reach a new therapeutic level of the disease. Consequently, the problem of $\mathrm{HV}$ is of scientific interest and practical importance.
\end{abstract}

Keywords: hemorrhagic vasculitis, children, herpes simplex virus, cytomegalovirus, Epstein-Barr virus, human herpesvirus.

\section{Frequency and Prevalence of Hemorrhagic Vasculitis}

The analysis of literature data shows that hemorrhagic vasculitis (HV) can develop at the age of 5 months to 89 years and is the most common in children aged 4-6 years when the incidence rate is 70 cases per 100,000 children. Men and women suffer equally often. With age, the frequency of development of SchonleinHenoch purpura (SHP) gradually decreases. Among adults, persons up to 30 years of age predominate. The development of the disease after 60 years is a rarity. In general, the incidence of SHP is $13-20$ cases per 100000 people [1-3].

According to other literature data, the frequency of symptoms of HV is 14 cases per 100,000 of the population. The prevailing age is up to 20 years ( $40 \%$ of patients). The predominant sex is male (2:1). The peak incidence of HV occurs in the spring [4-7].

The frequency of development of SHP does not depend on race and ethnicity, at the same time, reliable correlation of the incidence with a time of year was noted. Thus, the highest incidence is observed in autumn, winter and spring, while in half of the cases in children the development of the disease is preceded by acute respiratory infection, which can indirectly indicate the infectiousdependent nature of the disease $[1,6,7]$.

The retrospective analysis of 337 cases of SHP, Zhao and Li (2017), whose goal was to determine the differences in morbidity, causes, clinical manifestations, prognosis in children and adults with SHP, showed that the SHP frequency in children in autumn and winter was higher than in adults $(\mathrm{P}<0.05)$. The frequency of occurrence of $\mathrm{HV}$ in children was higher than in adults $(\mathrm{P}<0.05)$. The authors concluded the following: HV predominates mainly in children, especially in children younger than 10 years old. In comparison with adult patients, in children with HV, the disease is preceded by infection of the upper respiratory tract with relatively "easy" kidney damage and better prognosis [8].
HV is a fairly common disease in childhood, which is difficult; it often takes a recurrent course with the involvement of kidneys in pathological process, with violation of their function and formation of chronic glomerulonephritis with outcome in chronic renal failure [3, 9-11]. The study of various aspects of the course of HV will help to reach a new therapeutic level of this disease. In this regard, the problem of $\mathrm{HV}$ is of scientific interest and practical importance.

HV (synonyms: anaphylactic purpura, capillary toxicosis, Schonlein-Henoch disease - purpura, rheumatoid purpura) - is a systemic disease caused by generalized inflammation of small vessels, arterioles, small capillaries, perivascular edema and cell infiltration with neutrophils and erythrocytes; its clinical manifestations are often sharp, with simultaneous appearance of a range of symptoms: characteristic rash, sometimes accompanied by angioedema, articular syndrome, abdominal symptoms and renal disease with varying degrees and frequency [2, 5-7, 11-13].

In their article, Croche Santander Borja, Campos Elena, Sanchez Adela, Marcos Laura, Diaz Isabel, Toro Cristobal (2016) conclude that SHP accounts for the majority of cases of systemic vasculitis in children. The clinical picture is characterized in most cases by purpura, glomerulonephritis, arthralgia and abdominal pain. The authors note that although the manifestation of urogenital organs in $\mathrm{HV}$ in the form of proliferation of testicles and scrotum is widespread, the participation of genital organs remains extremely rare complication [11].

The etiology of most primary vasculitis is unknown. Their occurrence in children can contribute to frequent acute infectious diseases, foci of chronic infection, drug allergy, hereditary predisposition to vascular or rheumatic diseases. Bacterial or persistent viral infections, allergies or burdened allergic anamnesis are two factors that form the background for hypersensitivity of an organism or act as a trigger, provoking factors $[6,7,9,10,13-16]$. Changes in HV in the damaged area of the vessel are diverse from ischemia to hemorrhage, necrosis, and infarction. The degree 
of vascular disorders depends on the caliber of affected arteries and state of collateral circulation [14]. Great importance in the development of vasculitis is formation, circulation and deposition on the walls of vessels of immune complexes (CIC), the excess of which activates the complement system (C). As a result, large immune complex $(\mathrm{AG}+\mathrm{AT}+\mathrm{C})$ is formed, which settles on vascular endothelium and damages it. In response to the damage, tumor necrosis factor, platelet activation factor, protease are developed, which lead to increased adhesion and aggregation of platelets, the formation of platelet thrombi, development of local hypercoagulation, antineutrophil cytoplasmic antibodies. Immune proliferativedestructive inflammation of the wall of arteries of different caliber leads to damage to the vascular endothelium, increased vascular permeability, hypercoagulation with violation of blood flow, ischemia in the area of vascular injury. It is believed that deposition of large IC with HV, causes damage to skin and joints, and small IC cause abdominal syndrome and kidney lesions [2, 5-7, 9, 11, 13]. In the initial period of vasculitis, general manifestations of nonspecific inflammatory syndrome are observed: subfebrile or febrile fever, arthralgia, weight loss, symptoms of peripheral and visceral vascular disorders, mild anemia, peripheral blood leukocytosis, increased ESR, signs of hypercoagulation, dysproteinemia, increased C-reactive protein, $\operatorname{IgA}$, circulating immune complexes and cryoglobulins $[12,13,17]$. The peculiarity of the clinical manifestations is caused by localization of vasculitis, the caliber of affected vessels, the prevalence of pathological process, peculiarities of morphological changes (predominance of destructive or proliferative processes), the degree of hemodynamic disorders and ischemia of organs and tissues. The vascular genesis of massive hemorrhages and necrosis in herpesviral encephalitis has been proved [2, 5-7, 9, 11, 13]. Vivid evidence of morphological changes in blood vessels that can be visualized during these infections are the data of Kazakhstan and foreign researchers, indicating the development of coronaritis after acute and more frequent on the background of chronically ongoing Epstein-Barr virus (EBV) infection. Coronary lesions were found in $55 \%$ of children who underwent EBC-infectious mononucleosis with fever lasting more than 5 days. It is known that ability of viruses to cytopathic effect, showing tropism to blood vessels, is important for herpesvirus infection. Vascular damage in EBV is registered in $7-30 \%$, and with cytomegalovirus (CMV) - in 8\% [18-21].

\section{Herpes Persistent Infection in the For- mation of $\mathrm{HV}$}

More than $90 \%$ of people are infected with herpes viruses. At least in $20 \%$ of them, infectious agents cause serious health problems. Having once got into the human body, the virus remains in it for life in the latent or persistent state, undergoing reactivation under favorable conditions. The main properties of herpesviruses include the following: ubiquitarity, universal susceptibility, opportunism, pantropism, ability to use various transmission mechanisms, the complex strategy of parasitism, immunosuppression and oncogeneity. To date, there are 8 types of known viruses of herpes family that cause diseases exclusively in humans. These include: herpes simplex virus type 1 (HSV-1); HSV-2 (genital herpes virus or human herpesvirus type 2 (HHV-2); varicella-zoster/herpes zoster virus or HHV-3; EBV or HHV-4; CMV or HHV-5; HHV6; HHV-7; HSV-8 or human Kaposi's sarcoma virus (HKSV) [18-23].

To alphaherpesvirinae subfamily, HHV-1, HHV-2 and HHV-3 belong, to betaherpesvirinae subfamily - HHV-5, HHV-6, HHV-7, and to gammaherpesvirinae subfamily - HHV-4 and HHV-8. In this case, representatives of one subfamily possess some common biological properties.

Widespread infection with herpesviruses in the human population, their immunotrophy, activation in immunosuppression of various genesis, indicate the association of herpesvirus infections with the development of somatic pathology, namely with HV. Viruses of the herpetic group have pronounced tropism to epithelial, endothelial cells, therefore one of the manifestations of herpesvirus infections can be the development of different types of vasculitis. The most common of systemic vasculitis group is HV. It was found that the HHV-6 in children with primary infection and with its reactivation causes infectious erythema with symptoms of vasculitis, which is observed 3 times more often than in case of EBV and CMV. This problem has been little studied and requires further investigation [18-22, 24].

Thus, B.Z. Garty and U. Pollak (2006) described the case of HV caused by herpes virus of the first type [25].

Single cases describe the case of HV with HSV- - S.B.I. Snider and C.S. Jacobs in 2014 [26].

In the scientific work by O.N. Egorova, R.M. Balabanova, G.N. Chuvirova, the analysis was conducted of antibodies to CMV, HSV-1, HSV-2 and EBV in patients with vasculitis in order to clarify clinical correlations. The results of the study showed the following: IgG antibodies to CMV were detected in $79 \%$, VCAIgG antibodies to EBV in $70.3 \%$, EA-IgG antibodies to EBV in $56.6 \%, \mathrm{IgG}$ antibodies to HSV-1 in $42,1 \%$ of patients. Active CMV infection was diagnosed in $27.8 \%$ of cases, active EBV infection in 56.6\%, combinations of CMV and EBV infection in $46.9 \%$ of cases. The authors conclude the following: in the differential diagnosis of systemic vasculitis, the possibility of infection with CMV and EBV should be considered [27].

Among the known 8 viruses of the herpes family, the most common infection in children is CMV, EBV, HSV-1, HSV-2 and HHV-6. In $80-90 \%$ of children, CMV infection is asymptomatic, in latent form, in which life-long persistence of the virus is possible. By 3 years of life, up to $20-70 \%$ of children become carriers of the EBV. HHV-6, which in children can cause erythema with symptoms of vasculitis (sudden erythema) has been comparatively recently studied. Primary infection with HSV occurs in $40 \%$ of cases already at an early age [18-20,28].

In the meta-analysis by H.I. Chan, Y.L.I. Tang (2016) of HV involving kidneys, thirteen studies (2,398 children) revealed 20 possible and 13 significant risk factors associated with ShonleinHenoch purpura, with the following meta-analysis of odds ratios (OR) and weighted mean difference (WMD) with 95\% confidence intervals: higher age $(0.90,0.61-1.19)$; age $>10$ years $(3.13,1.39$ 7.07); male gender (1.36, 1.07-1.74); pain in the abdomen $(1,94,1,24-3,04)$; gastrointestinal bleeding $(1.86,1.30-2.65)$; angina pectoris $(3.38,1.17-9.80)$; persistent purple $(4.02,1.22-13.25)$; relapse $(4.70,2.42-9.14) ; \quad$ WBC $>15 \times 109 / \mathrm{L} \quad(2.42,1.39-4.22)$; platelets $>500 \times 109 / \mathrm{L}(2.98,1.22-7.25)$; increased antistreptolysin $\mathrm{O}$ (ASO) $(2.17,1.29-3.64)$; and reduced component of 3 (C3) $(3.13,1.62-6.05)[29]$.

In the article by M. Dylewska, M. Wieliczko, HV is described as IgA-vasculitis, which is a systemic inflammation of small vessels associated with precipitation of $\operatorname{IgA}$ antibodies in the vascular wall. Typical clinical symptoms are skin lesions (purpura), joint pain, abdominal discomfort and kidney failure (the most common hematuria/proteinuria). The authors note the high incidence of the disease among children, who have a more favorable course of HV [30].

Summing up the literature and the results of the authors' own research, in a systematic review of the literature, V. Ramelli, S.A. Lava, G.D. Simonetti, M.G. Bianchetti, G.P. Ramelli, G.P. Milani describe cases of vesicular rashes in children with Schonlein-Henoch syndrome, which does not exclude persistent viral infection. Ten children, from 666 selected pediatric cases of Schonlein-Henoch, had a vesicle rash, which was $1.5 \%$. The authors also found 41 individually documented cases of SchonleinHenoch syndrome with vesicular rashes [31].

In the work by L.L. Chelpan [32], the role of infectious agents in the development of HV in 62 children was studied. A half of children of school age and adolescents with HV found an association with streptococcal, and in some patients in combination with persistent viral infection. It was found that during the association of $\mathrm{HV}$ with streptococcus persistent viral infection was detected in 
practically all preschool children (5 of $6-83.3 \%$ ), and also in the majority of schoolchildren ( 9 out of $13-69.2 \%$ ). At the same time, in younger children markers of several viruses (herpes of type 1,2, CMV, Epstein-Barr) were detected, more often in the active stage of infection. In schoolchildren more often one of the viruses in the inactive, chronic stage of infection was detected. During the replication of the herpetic virus, patients underwent antiviral therapy (acyclovir 10 days in combination with viferon or laferobion for 1.5 months) [32].

In the study by N.Yu. Yegorova, L.N. Guseva, N.A. Guseva, E.V. (2008), 254 children aged 6 months to 14 years (163 patients with infectious mononucleosis, 41 with vasculitis syndrome, $50-$ clinically healthy children) were examined and analyzed for detection of markers of herpes viruses of types IV, V and VI. For the established manifest form of herpetic infection, the detection of replication markers was of clinical importance. The positive test for heterophilic AT was characteristic of Epstein-Barr infection. The expressed proliferative reaction of the lymphoid and reticulistocystic system is more often observed with active replication of Epstein-Barr and HHV-6, and vasculitis syndrome - with active replication of CMV and HHV-6. When analyzing the etiological structure of vasculitis syndrome in children, it is noted that $68 \%$ occupy mixed forms of the disease. Less common were vasculitis as manifestation of monoinfection in $42 \%$ of cases, with prevalence of type 6 as etiologic factor of CMV and HHV (Epstein-Barr - 3\%, CMV - 20\%, HHV-6 - 19\%, EpsteinBarr+CMV - 13\%, CMV+HHV-6 - 25\%, Epstein-Barr+HHV-6 $10 \%$, Epstein-Barr+CMV+VChV-6 type $-10 \%$ ). That is, in patients with vasculitis syndrome, active replication of CMV (68\%) and HHV-6 (64\%) was more frequent, compared to the active replication of Epstein-Barr, which is noted almost half as often $(36 \%)$ [33].

X. Murakami, S. Takahashi, Y. Kawakubo, N. Kinukawa, S. Funaki, K. Harada in 2008 described the case of a teenager with SHP and intracranial hemorrhage, possibly, as the authors note, associated with persistence of herpesvirus infection - CMV [10].

In the scientific study, the purpose of which was to study the characteristics of the haemostatic system in children with HV and relationship with activity and clinical manifestations of the disease, by the authors N.S. Podchernyaeva, M.A. Kudryashova, E.V. Frolkova, E.A. Korotkova, N.G. Dashkova (2016). The following conclusions were drawn: due to the close relationship between coagulation and inflammation processes the values of some coagulation and fibrinolytic systems, endothelial activation markers can be used to determine the level of clinical activity, and can also be considered as predictors of nephritis, severe skin lesions in HV in children [34].

The authors T.J. Kummerle-Deschner and S.M. Benseler (2015) conducted the literature review of $\mathrm{HV}$, various variants of $\mathrm{HV}$ in children are presented [9].

The research conducted by O.I. Sonina, E.G. Kikinskaya, G.A. Lyskina, G.A. Zinoviev (2008) showed the important role of infectious factors in the development and nature of the course of HV in children. Thus, in the study of 108 children with HV, $36.7 \%$ of children had persistent herpesvirus infection. The definition of infectious factors in HV makes it reasonable to use antibacterial and antiviral treatment in the case of $\mathrm{HV}$ associated with herpes simplex infection. It was revealed that of 105 patients who recovered or had sustained long-term remission, $90(86.7 \%)$ relapsed after the treatment of detected infections [16].

\section{Conclusion}

When summarizing the data in the reviewed and summarized reviews of articles, it is noted that the etiology and pathogenesis of many vasculitis in childhood are still unknown.

It should be noted that there is currently no consensus among researchers on the role of herpesviral infections in the development of HV. In recent years, the opinion has been formed, confirmed by several researchers, that there is no significant predominance of any one agent in the etiological structure of HV. The presented literature data and information on the etiologic structure of HV diseases, although quite numerous, are contradictory. It is hard to argue with the opinion of some authors who consider the herpespathetic infection a leading factor in the development of HV Widespread infection with herpesviruses in the human population, their immunotrophy, activation in immunosuppression of various genesis, indicate the association of herpesvirus infections with the development of somatic pathology, namely with HV. Viruses of the herpetic group have pronounced tropism to epithelial, endothelial cells, therefore one of the manifestations of herpesvirus infections can be the development of different types of vasculitis.

\section{References}

[1] Dolezalova P, Cummings C, Southwood TR (2002), Morbidity of Henoch-Shonlein purpura, Kawasaki disease and rare vasculitis in children of different ethnic origin. Lancet, 360, pp: 1197-1202.

[2] Hung SP, Yang YH, Lin YT et al (2009), Clinical manifestations and results of Henoch-Shonlein purpura: comparison between adults and children. Pediatrician Neonatol, 50 (4), pp: 162-168.

[3] Jauhola O, Ronkainen J, Koskimies O (2010), Renal manifestations of Henoch-Shonlein purpura in 6-month prospective study of 223 children. Archives of Disease in Childhood, 95 (11), pp: 877-882.

[4] Magichnost S, Balma-Mena A, Pope E, Weinstein M (2010), Bullous Henoch-Schönlein purpura in children: report on 6 cases and review of the literature. Clinical Pediatrics (Philadelphia), 49(11), pp: 1033-1037.

[5] Hospach T, Klaus G, Holl-Ulrich K et al (2008), Schoenlein-Enoch Purpura. Clinical Pediatrics, 220 (1), pp: 47-52.

[6] Saulsbury FT (2010), Purpura Henoch-Schönlein. Current Opinion in Rheumatology, 22 (5), pp: 598-602.

[7] Weller F, Hospach T, Dannecker G, Huppertz HI (2007), Schoenlein-Enoch Purpura. Pediatric practice, 70, pp: 77-92.

[8] Zhao L, Li Y (2017), Retrospective analysis on 337 cases of sep Henoch-Schonlein purpura. Zhonq Nan Da XueXueBao Yi Xue Ban, 42 (1), pp: 72-77, https://doi.org/10.11817/j.issn.1672-7347.2017. 01.012 .

[9] Kummerle-Deschner JB, Thomas J, Benseler SM (2015), Childhood vasculitis. Zeitschrift fur rheumatologie, 10(74), pp: 863.

[10] Murakami X, Takahashi S, Kawakubo Y, Kinukawa N, Funaki S, Harada K (2008), Teenager with glomerulonephritis purpura Henoch-Shonline and intracranial hemorrhage, possibly secondary to reactivation of latent CMV. Pediatrics International, 50(1), pp: $112-115$.

[11] Croche Santander B, Campos E, Sanchez A, Marcos L, Diaz I, Toro C (2017), Purpura de Schönlein - Henoch con afectacion peniana. Caso clinico. Archivos argentinos de pediatria, 4(115), pp: 249-251.

[12] Kharlamova FS, Egorova NYu, Shamsheva OV, Walts NL, Denisova AV (2016), HV on the background of actively persisting herpesvirus infections. Attending physician, 9, pp: 74-77.

[13] Okhotnikova EN, Gladush YuI, Ivanova TP (2010), Systemic vasculitis in the practice of pediatric allergist. Clinical immunology, allergology, infectology, 4, pp: 6-21.

[14] Kharlamova FS, Uchaikin VF, Legkova TP, Feldfiks LI (2012), Combination therapy with persistent herpesvirus infection in frequently ill children. Children's infections, 4, pp: 31-36.

[15] Bokova AG (2010), Herpesvirus infections in children - urgent problem of modern clinical practice. Infant Infections, 2, pp: 54-59.

[16] Sonina OI, Kikinskaya EG, Lyskina GA, Zinovieva GA (2008), The role of infection in the development and course of ShenlaineHenoch disease in children. Pediatrics, 87(2), pp: 35-39.

[17] Karetnikova VM, Petrunko IL (2017), Clinico-expert case of eosinophilic granulomatous vasculitis. Asta biomedical scientifica, 3(2), pp: 106-109.

[18] Kazmirchuk VV, Maltsev DV (2010), Retrospective analysis of use of Geprimun-6 in patients with infection caused by HSV of type 6 . Clinical immunology, allergology, infectiology, 6(34), pp: 64-70.

[19] Bao L, Cowan MJ, Dunham K et al (2012), Adoptive immunotherapy with CMV-specific cytotoxic T lymphocytes for stem cell transplant patients with refractory CMV infections. Journal of Immunotherapy, 35(3), pp: 293-298.

[20] Doubrovina E, Oflaz-Sozmen B, Prockop SE et al (2012), Adoptive immunotherapy with unselected or EBV-specific T cells for biopsy- 
proven EBV+ lymphomas after allogeneic hematopoietic cell transplantation. Blood, 119(11), pp: 2644-2656.

[21] Kudashov NI, Sukhikh GT, Orlovskaya IV, Ozerova OE, Faizullin LZ (2011), Herpes-viral infection in newborns. Zemsky doctor, 5(9), pp: 9-12.

[22] Lalezary M, Recchia FM, Kim SJ (2012), Treatment of congenital CMV retinitis with intravitreous ganciclovir. Archives of ophthalmology, 130(4), pp: 525-527.

[23] Nigro G, Adler SP, Parruti G et al (2012), Immunoglobulin therapy of fetal CMV infection occurring in the first half of pregnancy a case-control study of the outcome in children. The Journal of Infectious Diseases, 205(2), pp: 215-227.

[24] Duse M, Iacobini M, Leonardi L et al (2010), Transient hypogammaglobulinemia of infancy: intravenous immunoglobulin as first line therapy. International Journal of Immunopathology and Pharmacology, 23(1), pp: 349-353.

[25] Garty BZ, Pollak U, Scheuerman O, Marcus N, Hoffer V (2006), Acute hemorrhagic edema of infancy associated with herpes simplex type 1 stonatitis. Pediatric Dermatology, 23(4), pp: 361-364.

[26] Snider SB, Jacobs CS, Scripko PS, Klein JP, Lyons JL (2014) Hemorrhagic and ischemic stroke secondary to HSV type 2 meningitis and vasculopathy. The Journal of NeuroVirology, 20(4), pp: 419-22, doi:10.1007/s13365-014-0253-7.Epub 2014 May 8.

[27] Eqorova ON, Balabanova RM, Chuvirov GN (2003), Significance of antibodies to herpesviridae viruses detectable in rheumatic diseases. Terapevticheskii arkhiv, 70(5), pp: 41-45.

[28] Moraru M, Carbone J, Alecsandru D (2012), Intravenous immunoglobulin treatment increased live birth rate in a Spanish cohort of women with recurrent reproductive failure and expanded CD56(+) cells. American Journal of Reproductive Immunology, 68(1), pp: $75-84$.

[29] Chan H, Tang YL, Lv XN, Zhang GF, Wang M, Yang HP, Li Q (2016), Risk Factors Assjciated with Renal Involvement in Childhood Henoch - chonlein Purpura: A Meta-Analysis. PLoS One, 11(11), doi: 10.1371/journal pone.0167346.

[30] Dylewska M, Wieliczko M (2016), IgA vasculitis (HenochSchonlein Purpura). Wiadomości Lekarskie, 69(5), pp: 711-713.

[31] Ramelli V, Lava SA, Simonetti GD, Bianchetti MG, Ramellli GP, Milani GP (2017), Blistering eruptions in childhood HenochSchonlein syndrome:systematic review of the literature. European Journal of Pediatrics, 176(4), pp: 487-492.

[32] Chelpan LL (2011), Features of therapy for HV associated with streptococcal infection. Bukovins'kiy medichniy visnik, 1(15), pp: $107-109$

[33] Egorova NYu, Guseva LN, Guseva NA, Novosad EV, Rakhalina AA, Rogova LA, Uchaikin VF (2008), Significance of markers of herpes viruses for state evaluation of children's health. Children's infections, 6, pp: 62-69.

[34] Podchernyaeva NS, Kudryashova MA, Frolkova EV, Korotkova EA, Dashkova NG (2016), Clinical significance of hemostatic disorders in iga-vasculitis (henoch-schonlein) in children. New Armenian Medical Journal, 3(10), pp: 43-51. 